\title{
Social Media Usage in e-Government: Evidence from Suriname
}

\author{
Muhammad Firdaus Samijadi \\ School of Public Affairs, \\ University of Science and Technology of China, \\ Hefei, Anhui, 230026, China. \\ E-mail: feydaus@mail.ustc.edu.cn
}

Received: April 20, 2017 Accepted: June 6, 2017 Online published: June 12, 2017

doi:10.5296/jpag.v7i2.11268 URL: https://doi.org/10.5296/ jpag.v7i2.11268

\begin{abstract}
Social Media has made its' way of playing an important role in e-Government implementation strategies. Many governments include social media as a tool to approach and engage its' citizens, to increase transparency, trust and online participation. Although social media is not yet fully understood by governments on how to effectively utilize social media as a tool to be beneficial to the government and the general public. This research focuses on the Social Media activity of the Government Departments of Suriname. With around 1.9 billion active users, Facebook is one of the largest social media platforms in the world. This study furthers analyzes how active social media accounts are being used by the departments and how online users respond to departmental online activities. In order to achieve the goal of this paper, the 14 social media accounts of Suriname government departments will be taken as a case study. Several accounts indicate that government to citizen engagement show much potential for citizens' active online participation. While the use of social media in e-Government initiatives is a feasible approach to successful implementation, there are still some improvement governments should take into consideration to increase online participation and fulfilling the needs of their citizens.
\end{abstract}

Keywords: Suriname, e-Government, social media, Facebook

\section{Introduction}

In the 1980, the advancement of information and communication technologies have substantially adjusted peoples' productivity and style of living, which has also had an influence on traditional social structures (Zhang et al., 2009). In the 1990s, the world witnessed an increasing interest in reforming the public sector by using ICT as a platform for 
communicating with/ and providing services to the citizens. This internationally growing phenomenon was labelled as e-Government by the United Nations. Then over the past two decades e-Government has been considered an important public management reform as countries have sought out new methods to control cost and improve governmental organizational efficiencies (Larsson and Grönlund, 2014). As the result of direct and indirect forces of globalization, e-Government has become an important agenda in both developed and developing countries public management planning. The the developments in ICT has been faster than ever before and their advancements has added new dimension to promoting public services and support the process of development and good governance. It is accepted as an extensively and effective tool for service delivery because it can transform relations between citizens, businesses and the government. As governments look for better ways to approach their citizens, promote transparency and improve public service, social media technologies are constantly being integrated into governmental workplaces and have shown to be a very successful tool to improve public service delivery objectives. Social media is a composition of several web 2.0 technologies that allows its' users to communicate, interact, participate and engage with one another, may it be between citizens, businesses and/ or governmental. According to Kaplan and Heinlein (2010) the exact technologies used consist of wikis, microblogging, virtual worlds, crowdsourcing and social networking applications to name a few. Social Media is being utilized by all kinds of individuals and organizations. For individuals, the benefits of using social media have not only been for building basic social networks but also into building their own name and creating career possibilities and monetary profits (Tang et al. 2012). For business organizations, the benefits of utilizing social media make it easier for entrepreneurs to approach their customer and create a many possibilities to market their business to the online community. One of the major trends of e-Government is utilizing social media in research and practice of global e-Government implementations (Bertot et al., 2012). It creates opportunities for increasing effectiveness and approval of the public sector, by encouraging interaction and organization between different stakeholders, which has aided current government initiatives to achieve open government to increase transparency, participation and cooperation. (Lee and Kwak, 2012). For governments, the opportunities created by social media are immeasurable, information and perceptions from citizens can be considered into effective policy making, promote transparency through information dissemination on social media and collaborate with civil society to agree on decisions or to find solutions to government issues (Mergel, 2013). Social media is relatively still a new technology that needs better understanding in certain areas such its' benefits, risks, barriers and strategic use. Bertot et al., (2012) mentioned that the use of social media in government do offer critical opportunities for democratic participation, co-production and brainstorming for or solutions and innovation, thus the possibilities that social media can offer through interactivity. Even though government tend to focus more on social media by putting more faith in social media to interact with the general public, the shortage of evidence found in research to document and prove social media's business value in terms of ameliorating interactivity between government and civil society (Susanto and Goodwin, 2013).

Current e-Government initiatives and activities are being pursued with the use of social 
media, although it does not meet sufficient requirements yet to be an advantageous dialogue and feedback platform for government and the public. According to Kuzma (2010) communication between government and the public is technically supported sufficiently, but in reality, the utilization of social media is often one directional and does not promote interaction. However, many agencies are unwilling to evaluate their online interaction due to the shortage of clear objectives for e-Government, or are even obstructed due to applied laws and regulations (Magro, 2012).

\section{Relevant Literature}

\section{1 e-Government}

Although e-Government has gained much attention in recent years, there is no standard definition available for this term. Different governments, organizations and scholars define this term according to their own aims and objectives. Some broadly used definitions are listed below: According to Coleman (2006) e-Government is defined as the combination of electronic information-based services with the reinforcement of participatory elements to achieve the objective of balanced e-Government. Muir and Oppenheim (2002) defined e-Government as the delivery of online government information and services through the internet or other digital means. Kumar et al. (2007) defined it as the delivery of improved services to civil society through substantially changing the way governments manage information. In 2001 World Bank defined e-Government as a reference to the use by government agencies of information technologies that have the ability to transform relations with citizens, businesses, and other parts of government agencies so as to promote citizens' empowerment, improve service delivery, improve government efficiency, strengthen accountability and increase transparency. These technologies can serve a variety of different ends: better delivery of government services to citizens, improved interactions with business and industry, citizen empowerment through access to information, or more efficient government management. With benefits that can result in less corruption, increased transparency, greater convenience, revenue growth, and/or cost reductions. Thus, suggesting the use of information technologies in improving citizen to government interactions, cost-cutting expenditures and generating revenue and promoting transparency. UNESCO defines e-Government to Information and Communication Technologies that utilizes its advantages to improve the exercise of economic, political and administrative authority in the management of a country's affairs; this includes citizen's expression of their interests and exercising their legal rights and obligations. e-Government may be understood as the performance of public management via the electronic medium in order to assist in an efficient, speedy and transparent process of disperse information to the public, and other institution or agencies, and also for government administration activities. This definition conceptualizes the use of the electronic medium in the exercise of authority in the management of government affairs along with the expression of citizens' interests leading to greater transparency and efficiency. Abramson and Means (2001) also argued that e-Government is defined as the electronic interaction such as transaction and information exchange between the government, the citizens, businesses and employees. Backus (2001) mentioned that e-Government goal is to enable the interaction between government and citizens (G2C), improve inter-agency 
relationships $(\mathrm{G} 2 \mathrm{G})$, and establish efficient relationship between the government and business enterprises (G2B). One of the prominent models to measure the progress of e-Government initiatives and to determine a road map to reach the preferred levels of essential services is the Gartner research (2000) study titled "Gartner's Four Phases of e-Government Model". This research classifies e-Government into four specific stages and can serve as a referral to position where a project fits in the overall evolution of an e-Government implementation strategy. a.) Presence; b.) Interaction; c.) Transaction; and 4.) Transformation. An analysis of the country to determine in which phase a government currently is, is important when developing an e-Government strategy or implementation model. If the phase is identified, it becomes easier to formulate an integrated plan. According to Basu (2003), Identifying in which stage a developing country is, may help us understand the balance of expenditure to produce higher capabilities and to what extend those capabilities are being utilized. It is without argument that ICT is the main reason for modernization in developing countries, because investing in this sector enables their small economies to look into and increase their competitiveness as external service providers. There are currently many developing countries that are taking advantage of new innovative ideas that are arising by the usage of ICT, thus creating employment and positively influencing their socio-economic development.

\subsection{Social Media}

Social media is a composition of several web 2.0 technologies that allows its' users to communicate, interact, participate and engage with one another, may it be between citizens, businesses and/ or governmental. In practice, social media serves as a catchall phrase for a conglomeration of web-based technologies and services such as blogs, microblogs, social sharing services, text messaging, discussion forums, collaborative editing tools, virtual worlds, and social networking services (Hansen et al., 2011). Social media became a platform that is broadly used by individuals in order to easily connect and communicate with each other online. It is defined by Harris and Rea (2009) as a perceived second generation of Web development and design that facilitates communications and secures information collaboration, interoperability and sharing on the World Wide Web. It is obvious that based on this definition the major function of Social Network is communication and interaction. e-Government has evolved into two major stages that focus on information sharing and communication. One of the advantages of social media is it creates new ways of communication in which people can share information within their special profile and view content and information in other profiles within a certain environment. Social Media is shifting people from being content readers to become content creators and publishers. This became an important feedback device through which people have two-way information flow. Various types of content can be acquired from and shared on social media sites such as news, documents, advertisements, videos and music. Users can benefit from both uploading their own content or share others and disseminate content throughout their network. Because of the rapid growth of social media sites usage, a variety of social media tools with special and attractive functions are available which prioritize on getting people's attention and attract them into joining these sites. Based on that, social media sites can be categorized into the 
following main categories based on their different functions: 1.) Directories that provide résumé writing functions with rating capabilities performed by clients and colleagues; 2.) Communication channel that provides information and text dissemination functions on an ongoing and up-to-date basis; 3.) Communities and rating sites that serve less formal interactions within closed sites and can be used for events promotion; 4.) Archiving and sharing sites that used for storing and sharing videos, documents and slides with active feedback channels. Social media is not only an Information Technology application but it is also an important communication tool that affects how individuals interact, communicate and connect with each other.

Moreover, social media provides individuals with an easy way to access information they need and build a relationship they want through these platforms. These tools differ considerably in their purposes and approaches, but they share a prominence on enabling users to communicate, interact, edit, and share content in a social environment (Porter, 2008; Tepper, 2003). Unlike traditional media, social media depends on user generated content, which refers to any content that has been created by individuals or the general public as opposed to experts. Traditional media such as radio, books, and network television are mainly intended to be a broadcast platform, whereas social media is designed to be a dialogue platform (Porter, 2008). This dialogue platform allows large groups of geographically dispersed users to create important information resources (Benkler, 2002), find solutions to challenging problems by tapping into unique and rare expertise (Brabham, 2008), and gain diverse perceptions and perspectives through discussion. Social Media Services differ in their scope, the type of content being shared, the pace of interaction, the types of connections between users and items, who can control the data, and data retention policies (Hansen, 2011). Small changes in the design of social media tools and policies around them can be essential to their success and failure (Maloney-Krichmar \& Preece, 2005; Preece, 2000). Individuals and government agencies have enthusiastically embraced the use of social media for government purposes. Government employment of social media offers several key opportunities for the technology (Bertot, Jaeger, Munson, \& Glaisyer, 2010). Much government activity is now focused on social media, with social media becoming a central component of e-Government in a very short period of time (Bertot, Jaeger, \& Grimes, 2010, 2010b)

\subsection{The Interactivity of Government Social Media Usage}

Social media has the ability to provide more interactive features for public to understand e-Government. The idea of interactivity dates back to at least 40 years, into fields such as cybernetics and automation studies. In concurrent communication studies, interactivity has often been viewed as a not so worthy of a study, but rather as an alternate form for communication, with some expectations (Huhtamo, 1998). Rogers is one of the first to offer a definition of interactivity applicable to online contexts, he described it as a new communication system that talks back to users, normally with a computer as one of the components of the process. He further explains that interactivity is a variable, and a given communication technology that can be more or less interactive (Rogers, 1986). The notion of interactivity is tightly associated with e-Government. Van Dijk (2006) recognizes and explicated the various characteristics of interactivity. He identified four levels of interactivity 
between human beings, between human beings and mediator machines, between human beings by means of media, and between media or between machines. Based on the previous literature review shown above, we know that the concept of interactivity is utilized to gauge communication efficiency and effectiveness between a government and civil society. The interactivity between government and the public is classified into two types, one-way interactivity and two-way interactivity. Nowadays many e-Government initiatives often focus on one-way interactivity, which means only providing information to citizens and the rest. Two-way interactivity of social media application is still lacking in governments around the world. While social media can promote the government-citizen interactions and can eventually even drive innovation. Studies on interactivity of governments' use of social media is limited in many different areas (Welch and Fulla, 2005; Suen, 2006).

\section{Research Methodology}

In this research, a case study is chosen as the approached method due to the exploratory nature of this study. Case studies have been extensively used in social media research such as by Kuikka and Äkkinen (2011) in their study of determining challenges in organizational social media, adoption and use, Heath and Singh (2012) in their study of Social Media Engagement, Lien and Cao (2014) in their study of examining wechat users' motivations, trust, attitudes, and positive word-of-mouth and Hao et al., (2016) in their study of how to strengthen the social media interactivity of e-Government. A case study, as opposed to a lab study, has its advantages in investigating the occurrence in their natural environment (Benbasat et al., 1987). Quantitative data such as number of followers, posts, shares, likes and comments will be collected in this study.

\subsection{Case Study}

Suriname is the smallest independent country in South America that is comprised of 10 administrative districts, with a total land area of $163820 \mathrm{~km} 2$ and a total population of 541 638 (ABS, 2014). Suriname has witnessed a steadily growing economy in the past few years, by prudent economic and fiscal management by the Surinamese government (UNDP, 2008). Human development and public sector reform is high on the government agenda, which can also be noticed in the "multi annual development plan 2011-2016". The goal of this plan is to realize sustainable human development through economic growth and also incorporating achieving the Millennium Development Goals. In 2012 the government installed an e-Government committee with the objective of developing and implementing a national e-Government Strategy. The e-Government committee is committed to achieving the following goals by 2020 at the latest:

- That all government services are available online.

- That all governmental institutions are connected to each other.

- That the people register of Suriname becomes the basic file of all services.

- That every family in Suriname has an "information \& communication device".

- That every family in Suriname has access to the Internet. 
- That every Surinamese has a secure smart ID card.

- That every Surinamese can do digital payments at home and abroad.

These goals can only be achieved by fulfilling the preconditions. The e-Government Commission has identified the following preconditions for the moment and will work to fulfill it: a). Civil society is the central focus: process innovation will always be viewed from the perspective of the citizen, business or civil society; b). Total Connectivity: all ministries are connected to a high-speed connection. Service oriented Ministries, will have a direct and secure Internet access for citizen to make use of e-Services; c). Awareness is emphasized: awareness raising campaigns will come within the government, concerning safety. Also citizen awareness to use long-term cost-effective government e-Services; d). Mindset focuses on security: there must be a general culture and attitude of caution and security, for example by means of a 'Security Campaign' where government officials at all levels of government learn the security procedures and commit themselves to the new way of working; e). Inter-governmental agencies cooperation: to minimize the number of information sources (databases), which should eventually bring information to the general public through one central source, closer cooperation between the different ministries and semi-governmental organization is needed; f). Consistent focus of one government with one policy: uniformity in ICT (hardware and software, one corporate style). The government then radiates one face to the outside world. This increases security and strengthens the image towards citizens and businesses; g). Innovation is the measure of things: applying new technologies that are already being applied in other parts of the world. And introduce this in Suriname in a gradual and creative way; h). Impact on institutional reinforcement: Government and organized government institutions must be ICT-driven. This is essential for the citizens to take full advantage of the knowledge society; i). Designing adequate ICT laws and regulations: There must be a good legal framework for electronic transactions, protection of citizens (including minors) within cyberspace and the consolidation of intellectual property on innovations; $j$ ). Impact on statistical indicators: Statistical indicators are important for evaluating, measuring and monitoring implemented programs, implemented with support for ICT. Each development will take into account the incorporation of measurement indicators to evaluate and, if necessary, adjust them at regular intervals; k). Attention to multidisciplinary ICT applications: In addition to e-Government to improve public services, increasing transparency and reliability, other ICT applications will also receive their own attention:

- E-Business (including e-Commerce): the use of ICT for executing business processes and improved customer-oriented services;

- E-Learning: the use of ICT as the main medium for knowledge transfer;

- E-Environment: the use of ICT for environmental protection and sustainable use of natural resources, including the monitoring and management of climate change.

In 2013 the government of Suriname launched a central website portal (www.Gov.sr). The central website consists of 19 sub-websites, 1 for the Cabinet of the President, 1 for the Cabinet of the Vice-President, and 17 for Government Departments. The functions of this 
website include basic web presence, static and generic content, public relations, news information, and email enquiries for questions. These websites do not directly offer an interactivity function, but rather informs the general public of current government projects or activities.

\subsection{Data Collection}

The Process of Data collection started by visiting each of the Government Department portals from www.Gov.sr. By thoroughly examining the main web portal of each Government Department we were directed to their official social media page on Facebook. From the 17 government departments we were able to find 14 government department accounts. A website, called fanpagekarma.com, was used to collect data from the period of April $13^{\text {th }} 2017$ - May $10^{\text {th }} 2017$ a total of 28 days or 4 weeks to be exact. The official department accounts were then followed through the above mentioned website to collect relevant data, such as the follower count, growth rate, posts, shares, likes and the amount of comments.

\section{Results}

The data collected from following government social media pages show different popularity and activity amongst them. The number of followers on Facebook is one of the indicators of popularity amongst the users. Table 1 below summarizes the data collected in this research. From the 17 government departments, 14 of them manage a Facebook social media page. The Department of Justice and Police (min JusPol) does not manage a social media page, instead we used the official account of the Suriname Police Force (Korps Politie van Suriname) that is directly related to the Department, as their social media substitute. Department of Defense (Ministerie van Defensie) and the Department of Environmental Planning (Min.RoGB) do not manage or do not have a social media account on Facebook, during the period of this study.

Table 1. Statistics Data of Social Media accounts Followers and Growth

\begin{tabular}{|l|r|r|r|}
\hline Government Department & $\begin{array}{r}\text { Followers } \\
\text { Beginning }\end{array}$ & $\begin{array}{r}\text { Followers } \\
\text { End }\end{array}$ & $\begin{array}{r}\text { Weekly Growth } \\
\text { avg. }\end{array}$ \\
\hline Labor (Arbeid) & 4309 & 4360 & $0.29 \%$ \\
\hline Domestic Affairs (Biza) & 6678 & 6749 & $0.26 \%$ \\
\hline Foreign Affairs (Buza) & 2576 & 2578 & $0.0 \%$ \\
\hline Finance (Financiën) & 1620 & 1680 & $0.9 \%$ \\
\hline Commerce, Industry Tourism (HI\&T) & 3073 & 3297 & $1.7 \%$ \\
\hline Agriculture (LVV) & 7405 & 7609 & $0.67 \%$ \\
\hline Natural Resources NH & 588 & 590 & $0.0 \%$ \\
\hline Education, Science, Culture (Minowc) & 25640 & 25650 & $0.01 \%$ \\
\hline Public Works(OW,Transport en Com) & 3870 & 4978 & $5.65 \%$ \\
\hline Regional Development (RO) & 7354 & 7438 & $0.28 \%$ \\
\hline Social Affairs and Housing (SoZaVo) & 3089 & 3702 & $4.14 \%$ \\
\hline Sport and Youth (S\&J) & 13798 & 13858 & $0.11 \%$ \\
\hline Transport, Communication and Tourism & 2514 & 2509 & $-0.05 \%$ \\
(TCT) & & & \\
\hline Health (Volks Gezondheid) & 571 & 613 & $1.71 \%$ \\
\hline Police (JusPol) & 48059 & 49485 & $0.72 \%$ \\
\hline
\end{tabular}




\section{Al Macrothink}

Journal of Public Administration and Governance

ISSN 2161-7104

2017, Vol. 7, No. 2

The table above shows the number of followers each government account had at the start and at the end of this research. The social media account of Police has the highest number of followers of 49485 with a weekly average growth of $0.72 \%$, followed by department of Education with 25650 (minowc) at a $0.01 \%$ growth and then the Department of Sport and Youth (Sport \& Jeugdzaken) with 13858 followers at a weekly average growth of $0.11 \%$. This could be an indication that the citizens of Suriname, value security and education the most. The department of Public works (OW) and the department of Social Affairs and Housing (SoZaVo) showed the highest growth percentage wise, 5.65\% and $4.14 \%$ respectively. Transport Communication and Tourism is the only account that had a decrease in followers, during the period of this research.

Table 2. Data for the number of posts

\begin{tabular}{|l|r|r|}
\hline Government Department & Posts & Avg. Post p/d \\
\hline Labor (Arbeid) & 0 & 0 \\
\hline Domestic Affairs (Biza) & 8 & 0.285 \\
\hline Foreign Affairs (Buza) & 0 & 0 \\
\hline Finance (Financiën) & 0 & 0 \\
\hline Commerce, Industry Tourism (HI\&T) & 13 & 0.464 \\
\hline Agriculture (Lvv) & 26 & 0.928 \\
\hline Natural Resources NH & 2 & 0.0714 \\
\hline Education, Science, Culture (Minowc) & 12 & 0.428 \\
\hline Public Works(OW,Transport en Com) & 16 & 0.571 \\
\hline Regional Development (RO) & 0 & 0 \\
\hline Social Affairs and Housing (SoZaVo) & 0 & 0 \\
\hline Sport and Youth (S\&J) & 2 & 0.071 \\
\hline Transport, Communication and Tourism (TCT) & 0 & 0 \\
\hline Health (Volks Gezondheid) & 0 & 0 \\
\hline Police (JusPol) & 104 & 3.714 \\
\hline
\end{tabular}

Table 2 shows the number of post made on the accounts during the period of this research. Police (Juspol) posted 104 times on their page averaging 3.7 post per day. Department of Agriculture (LVV) had 26 posts, averaging 0.9 posts a day followed by Public Works with 16 posts, Commerce with 13 and Education with 12 posts with daily averages of $0.6,0.5$ and 0.4 respectively.

Table 3. Data of number of Likes, Comments and Shares

\begin{tabular}{|l|r|r|r|r|}
\hline Government Department & Likes & Comment & Shares & Total \\
\hline Labor (Arbeid) & 0 & 0 & 0 & 0 \\
\hline Domestic Affairs (Biza) & 94 & 9 & 25 & 128 \\
\hline Foreign Affairs (Buza) & 0 & 0 & 0 & 0 \\
\hline Finance (Financiën) & 0 & 0 & 0 & 0 \\
\hline Commerce, Industry Tourism (HI\&T) & 826 & 575 & 605 & 2006 \\
\hline Agriculture (Lvv) & 435 & 49 & 145 & 629 \\
\hline
\end{tabular}




\begin{tabular}{|l|r|r|r|r|}
\hline Natural Resources NH & 0 & 0 & 0 & 0 \\
\hline Education, Science, Culture (Minowc) & 1233 & 160 & 936 & 2.329 \\
\hline Public Works(OW,Transport en Com) & 700 & 110 & 515 & 1.325 \\
\hline Regional Development (RO) & 0 & 0 & 0 & 0 \\
\hline Social Affairs and Housing (SoZaVo) & 0 & 0 & 0 & 0 \\
\hline Sport and Youth (S\&J) & 100 & 2 & 1 & 103 \\
\hline Transport, Communication and Tourism (TCT) & 0 & 0 & 0 & 0 \\
\hline Health (Volks Gezondheid) & 0 & 0 & 0 & 0 \\
\hline Police (JusPol) & 10516 & 4204 & 8035 & 22755 \\
\hline
\end{tabular}

Table 3 shows the amount of likes, comments and shares the the accounts received during the course of this research. As in Table 2 it shows that Police had the highest number of posts on their page also receiving the highest total amount of responses. The accounts that did not post on their page showed zero response on their pages.

\section{Discussion}

Facebook is a very popular social media platform in the world with 1.94 billion active users in the first quarter of 2017(Statista), and an estimate of 290000 Facebook users and accounts in Suriname. The results of this exploratory study have shown that the use of social media by government departments can be successful if departments act according to the needs of the citizens. In this paper the social media accounts of government departments on Facebook was investigated, with the goal to identify the online activity of these departments. Police showed the highest amount of activity on their page with a high number of followers also with a high amount of responses on their page. The number of responses the pages received is highly related to the amount of online activity of the departments. Accounts that post often on social media have a high likelihood of receiving responses from citizens which can lead to the growth of the account. Currently, government departments seem to use Facebook simply as a way to inform the general public on their Facebook pages. Therefore, departments have not yet grasp the full usefulness of social media tools. Finding ways to make social media platforms become more useful to the general public should be one of the important objectives of e-Government initiatives to create awareness amongst citizens. Looking at the government social media accounts reveals that the followers are eager to know more about government activities.

\section{Conclusion}

The e-Government initiative of Suriname has shown much potential in engaging citizens through social media. However, improvement of their social media service delivery is necessary to increase online participation of its citizens. Understanding the needs of the online community should be a priority for the departments. Therefore, government social media accounts should focus more on creating a plan for posting or uploading regularly on their pages to keep the online community active and updated. Generating and disseminating useful information to fit the needs of the general public could make their page more popular amongst the online community. Furthermore, future studies should focus into the contents posted on government social media pages, including the comments made by the general 
public. Finally, future research can also focus on the behavior of the followers of government accounts, in order to understand what can encourage citizens in online participation.

\section{References}

ABS. (2014). Algemeen Bureau voor de Statistiek in Suriname. Retrieved from: http://www.statistics-suriname.org/

Abramson, M. A., \& Means, G. (2001). e-Government. Rowman \& Littlefield.

Ameerali, R. (2012). eGovernment Strategie 2012-2016 van de Republiek Suriname Werkdocument retrieved from: http://www.gov.sr/media/3045036/120529_egov_strategie_2012_2016_werkdocument.pdf

Backus, M. (2001). E-governance and developing countries: introductions and examples. International Institute for Communication and Development, Research Report No. 3, Netherlands.

Basu, S. (2004). E-government and developing countries: an overview. International Review of Law, Computers \& Technology, 18(1), 109-132.

https://doi.org/10.1080/13600860410001674779

Baum, Christopher, \& Andrea Di Maio. (2000). Gartner's four phases of e-Government model. Gartner Group, 12.

Brabham, D. C. (2008). Crowdsourcing as a model for problem solving: An introduction and cases. Convergence, 14(1), 75-90. https://doi.org/10.1177/1354856507084420

Benbasat, I., Goldstein, D. K., \& Mead, M. (1987). The case research strategy in studies of information systems. MIS quarterly, 369-386. https://doi.org/10.2307/248684

Benkler, Y. (2002). Coase's Penguin, or, Linux and "The Nature of the Firm". Yale Law Journal, 369-446. https://doi.org/10.2307/1562247

Bertot, J. C., Jaeger, P. T., \& Hansen, D. (2012). The impact of polices on government social media usage: Issues, challenges, and recommendations. Government Information Quarterly, 29, 30-40. https://doi.org/10.1016/j.giq.2011.04.004

Bertot, J. C., Jaeger, P. T., Munson, S., \& Glaisyer, T. (2010). Engaging the public in open government: The policy and government application of social media technology for government transparency. IEEE Computer, 43(11), 53-59.

https://doi.org/10.1109/MC.2010.325

Coleman, S. (2006). African e-governance-Opportunities and challenges. Ox-ford University Press, University of Oxford.

Hansen, D. L., Shneiderman, B., \& Smith, M. A. (2011). Social media: New technologies of collaboration. Analyzing Social Media Networks with NodeXL, 11-29.

https://doi.org/10.1016/B978-0-12-382229-1.00002-3

Hao, X., Zheng, D., Zeng, Q., \& Fan, W. (2016). How to strengthen the social media 
interactivity of e-Government: Evidence from China. Online Information Review, 40(1), 79-96. https://doi.org/10.1108/OIR-03-2015-0084

Harris, A. L., \& Rea, A. (2009). Web 2.0 and virtual world technologies: A growing impact on IS education. Journal of Information Systems Education, 20(2), 137.

Huhtamo, E. (1998). Seeing at a Distance-Towards an Archaeology of the "Small Screen". na.

Heath, D., \& Singh, R. (2012). Strategic Social Media Engagement.

Kaplan, A. M., \& Haenlein, M. (2010). Users of the world, unite! The challenges and opportunities of Social Media. Business horizons, 53(1), 59-68.

https://doi.org/10.1016/j.bushor.2009.09.003

Kuikka, M., \& Äkkinen, M. (2011, June). Determining the challenges of organizational social media adoption and use. In ECIS.

Kumar, V., Mukerji, B., Butt, I., \& Persaud, A. (2007). Factors for successful e-Government adoption: a conceptual framework. The electronic journal of e-Government, 5(1), 63-76.

Kuzma, J. (2010). Asian government usage of Web 2.0 social media. European Journal of ePractice, 9, 1-13.

Larsson, H., \& Grönlund, ̊. (2014). Future-oriented eGovernance: The sustainability concept in eGov research, and ways forward. Government Information Quarterly, 31(1), 137-149. https://doi.org/10.1016/j.giq.2013.07.004

Lee, G., \& Kwak, Y. H. (2012). An open government maturity model for social media-based public engagement. Government Information Quarterly, 29(4), 492-503.

https://doi.org/10.1016/j.giq.2012.06.001

Lien, C. H., \& Cao, Y. (2014). Examining WeChat users' motivations, trust, attitudes, and positive word-of-mouth: Evidence from China. Computers in Human Behavior, 41, 104-111. https://doi.org/10.1016/j.chb.2014.08.013

Magro, M. J. (2012). A review of social media use in e-Government. Administrative Sciences, 2(2), 148-161. https://doi.org/10.3390/admsci2020148

Maloney-Krichmar, D., \& Preece, J. (2005). A multilevel analysis of sociability, usability, and community dynamics in an online health community. ACM Transactions on Computer-Human Interaction (TOCHI), 12(2), 201-232.

https://doi.org/10.1145/1067860.1067864

Mergel, I. (2013). Social media adoption and resulting tactics in the US federal government. Government Information Quarterly, 30(2), 123-130. https://doi.org/10.1016/j.giq.2012.12.004

Muir, A., \& Oppenheim, C. (2002). National information policy developments worldwide I: electronic government. Journal of information science, 28(3), 173-186.

https://doi.org/10.1177/016555150202800301 
Porter, J. (2008). Designing for the social web (pp. 21-40). Berkeley: New Riders.

Preece, J. (2000). Online communities: Designing usability and supporting socialbilty. John Wiley \& Sons, Inc.

Rogers, E. M. (1986). Communication technology (Vol. 1). Simon and Schuster.

Suen, I. S. (2006). Assessment of the level of interactivity of e-Government functions. Journal of e-Government, 3(1), 29-51. https://doi.org/10.1300/J399v03n01_03

Susanto, T. D., \& Goodwin, R. (2013). User acceptance of SMS-based e-Government services: Differences between adopters and non-adopters. Government Information Quarterly, 30(4), 486-497. https://doi.org/10.1016/j.giq.2013.05.010

Tang, Q., Gu, B., \& Whinston, A. B. (2012). Content contribution for revenue sharing and reputation in social media: A dynamic structural model. Journal of Management Information Systems, 29(2), 41-76. https://doi.org/10.2753/MIS0742-1222290203

Tarmizi, H. (2016). e-Government and Social Media: A Case Study from Indonesia's Capital. Tepper, M. (2003). SOCIAL.

Van Dijk, J. A. (2006). Digital divide research, achievements and shortcomings. Poetics, 34(4-5), 221-235. https://doi.org/10.1016/j.poetic.2006.05.004

Welch, E. W., \& Fulla, S. (2005). Virtual interactivity between government and citizens: The Chicago Police Department's citizen ICAM application demonstration case. Political communication, 22(2), 215-236. https://doi.org/10.1080/10584600590933205

World Bank. (2001). e-Government and the World Bank. Issue Note, November 5.

World Health Organization. (WHO). United Nations Development Programme (UNDP) (2009). The energy access situation in developing countries. Available at [last accessed 3 December, 2010]: http://www. who. int/indoorair/publications/energyaccesssituation/en/index. html.

Zhang, P., \& Sun, H. (2009). The complexity of different types of attitudes in initial and continued ICT use. Journal of the American Society for Information Science and Technology, 60(10), 2048-2063. https://doi.org/10.1002/asi.21116

\section{Copyright Disclaimer}

Copyright for this article is retained by the author(s), with first publication rights granted to the journal.

This is an open-access article distributed under the terms and conditions of the Creative Commons Attribution license (http://creativecommons.org/licenses/by/4.0/). 